\title{
Cancer Incidence in the Kurdistan Region of Iraq: Results of a Seven-Year Cancer Registration in Erbil and Duhok Governorates
}

\author{
Karwan M-Amen ${ }^{1,2}$, Omiad S Abdullah' ${ }^{3}$,Ahmed M.S. Amin ${ }^{4}$, Zeki Ali Mohamed, \\ Bestoon Hasan $^{6}$, Mudhir Shekha ${ }^{7}$, Hastyar H Najmuldeen ${ }^{4,8}$, Fryad Majeed \\ Rahman $^{4}$, Zjwan Housein ${ }^{9}$, Ahmed M. Salih ${ }^{10}$, Amin Salih Mohammed ${ }^{2}$, Luqman \\ Rahman Sulaiman ${ }^{11}$, Basak Tahir Barzingi ${ }^{5}$, Dler Mahmood ${ }^{4}$, Hemin Esmael \\ Othman $^{12}$, Dara K. Mohammad ${ }^{13,14}$, Fahmi M. Salih ${ }^{15}$, Suad AS Khudhur Ali ${ }^{16}$, \\ Trefa S. Mohamad ${ }^{7}$, Kazhan Mahmood ${ }^{17}$, Galawezh O. Othman ${ }^{18}$, Mukhlis H. \\ Aali $^{7}$, Govand Qader ${ }^{7}$, Bashdar M. Hussen ${ }^{19}$, Farhang A. Awla', Shahab Wahhab \\ Kareem $^{20}$, Fikry A. Qadir ${ }^{7}$, Dilan M. Taher ${ }^{7}$, Abbas Salihi ${ }^{2,7 *}$
}

\begin{abstract}
Introduction: There are limited published data regarding the recent incidence trends of cancer in Iraqi Kurdistan. Methods: The present study assessed the epidemiological estimates of cancer incidence, as well providing a projection of future cancer trends in the upcoming decade by analysing the population-based cancer registry between 2013 and 2019, in both the Erbil and Duhok governorates. A retrospective analysis was performed on data retrieved from the Medical Statistics Department at the Ministry of Health, Kurdistan Regional Government (KRG). Results: The total number of female cancer patients was higher in both governorates, and the total incidence of patients with cancer increased by over 2x between 2013 and 2019 in Erbil and Duhok, from 73 to 174 patients/100,000 individuals for women, and 36 to 85 patients/100,000 individuals for men. Analysis indicated that the percentage of patients with cancer is projected to increase by $>2 x$ in the current decade, from 3,457 cases to 4,547 and 4,449 cases in the Erbil governorate; and from 1,365 to 2,633 and 2,737 cases in 2028 based on LSTM and bi-LTSM analysis in the Duhok governorate. Lung cancer (LC) and female breast cancer (BC) were the most prominent types of cancers diagnosed since 2013 in both the Erbil and Duhok governorates. Conclusion: The striking pattern of trends for both present and future cancer incidence rates require urgent solutions and comprehensive efforts to control risk factors that promote the increasing incidence of cancer in these two KRG governorates.
\end{abstract}

Keywords: Cancer incidence- cancer statistics- age-standardized rate- Kurdistan Region- Iraq

Asian Pac J Cancer Prev, 23 (2), 601-615

\begin{abstract}
${ }^{1}$ Department of Nursing, College of Nursing, Hawler Medical University, Erbil, Kurdistan Region, Iraq. ${ }^{2}$ Center of Research and Strategic Studies, Lebanese French University, Erbil, Iraq. ${ }^{3}$ Department of Statistics, College of Administration, Salahaddin University, Iraq. ${ }^{4}$ Department of Biology, College of Science, University of Sulaimani, Kurdistan Region, Iraq. ${ }^{5}$ Department of internal medicine, College of Medicine, University of Duhok, Iraq. ${ }^{6}$ Department of Cancer Registry, Cancer Control Unit, Erbil Directorate of Health, Erbil, Iraq. ${ }^{7}$ Department of Biology, College of Science, Salahaddin University-Erbil, 44002 Erbil, Kurdistan Region, Iraq. ${ }^{8}$ Medical Laboratory Analysis Department, College of Health Science, Cihan University of Sulaimaniya, Kurdistan Region, Iraq. ${ }^{9}$ Department of Medical Laboratory Technology, Health Technical College, Erbil Polytechnic University, Erbil, Iraq. ${ }^{10}$ Molecular microbiology \& Immunology, College of Medicine, University of Duhok, Duhok, Kurdistan Region, Iraq . ${ }^{11}$ Department of Medicine, College of Medicine, Hawler Medical University, Erbil, Kurdistan Region, Iraq. ${ }^{12}$ Scientific Research Centre, College of Science, University of Duhok, Duhok, Kurdistan Region, Iraq. ${ }^{13}$ College of Agricultural Engineering Sciences, Salahaddin University-Erbil, 44002 Erbil, Kurdistan Region, Iraq. ${ }^{14}$ Center for Hematology and Regenerative Medicine (HERM), Department of Medicine Huddinge, Karolinska Institutet, 14183 Stockholm, Sweden. ${ }^{15}$ Rizgary Oncology Center, Erbil Screening and prevention, Erbil Cancer Control Unit, Erbil Directorate of Health, Erbil, Iraq. ${ }^{16}$ Department of Nursing, Ministry of Health, Kurdistan Region, Iraq. ${ }^{17}$ Department of Midwifery, College of Nursing, Hawler Medical University, Erbil, Kurdistan Region, Iraq. ${ }^{18}$ Department of Biology, College of Education, University of Salahaddin Erbil, KRG-Iraq. ${ }^{19}$ College of Pharmacy, Hawler Medical University, Kurdistan Region, Iraq. ${ }^{20}$ Information System Engineering Department, Erbil Polytechnic University, Iraq. *For Correspondence: abbas.salihi@su.edu.krd
\end{abstract}




\section{Introduction}

Cancer is one of the leading causes of death worldwide, accounting for 9.6 million deaths in 2018. Particularly unfavourable outcomes are expected in developing countries where access to healthcare is limited, and there is an increase in risk factors, such as political and economic instability, and transitioning lifestyles toward Western lifestyles (Fitzmaurice et al., 2019). Despite the implementation of national cancer registries and control programs since 1974 in Iraq, the increase in the incidence of cancer and death is alarming (Board, 2018). According to recent estimates from the International Agency for Research on Cancer (IARC), $>25,000$ new cancer cases and 14,000 cancer-associated deaths in Iraq were reported in 2018, with BC, LC, leukaemia, bladder and colorectal cancer (CRC) being the top five most common types of cancer (Bray et al., 2018). To address this increasing burden, over the last two decades, the Iraqi Government as well as the KRG have introduced significant efforts to rebuild supporting infrastructures, seeking to increase health system capacities by creating cancer centres and improving the cancer registry system. However, there are very limited published data on recent trends of cancer incidence in the KRG.

The early reported cancer incidence rates for Erbil and Duhok were 50.0 and 61.5 cases/100,000 individuals, respectively. By contrast, in Sulaymaniyah the incidence rate showed an increasing trend from 38.5 cases/100,000 individuals in 2006 to 61.7 cases/100,000 individuals by 2013 (Khoshnaw et al., 2015). Hence, due to these limitations, significant gaps and challenges remain in performing cancer-related scientific research and moving toward reliable numbers through a meta-analysis of available data (Qader et al., 2020). The present study presents a comprehensive demographic, comparative, and epidemiological estimates of cancer incidence, as well as a projection of future cancer trends in the current decade (2020-2030) by analysing the population-based cancer registry from between 2013 and 2019 in both Erbil and Duhok governorates of the KRG. This may serve as an essential resource for decision-makers in planning and re-evaluating the effectiveness of currently implemented cancer control policies. Additionally, it opens novel avenues for basic and clinical research to determine the possible and preventable risk factors that may be associated with the increased cancer incidence in certain areas.

\section{Materials and Methods}

The present study was a retrospective investigation into the prevalence and incidence of cancer. All cancer cases included in the present study were diagnosed and registered in Erbil and Duhok governorates of the KRG between 2013 and 2019. The analyses were based on data collected from the Medical Statistics Department at the Ministry of Health, which were retrieved from all the primary cancer registry centres in both governorates.

The abstracted data for tumour sites were coded according to the International Classification of Disease
(ICD) using the 9th or 10th edition morbidity and mortality coding system (Steindel, 2010). The topography (primary site) and morphology (histology) of the malignancies were identified and coded by the ICD-Oncology system, as specified by the ICD for Oncology 3rd edition, published by the World Health Organization (WHO) (World Health Organization, 2003). The indices of the registered cases used serial numbers, names and site codes. Furthermore, to avoid duplicate registrations, the incoming notifications were double-checked against the registered data. The data were recorded using the WHO cancer registration system following the standards of WHO IARC (IARC, 2014). Codes given by the ICD for the data were maintained and presented in the current study.

Relevant variables including the number of hospitals and patients that participated in this study; patient names, places of residence and demographic data (sex and age groups); as well as details on their specific cancer (primary site, date of diagnosis, histology, grade, basis of diagnosis) were obtained. Data on the incidences were analysed as cases/100,000 individuals for each type of cancer. Two algorithms, long short-term memory (LSTM) model and bidirectional-LTSM (BI-LSTM) neural network with multilayer perceptron (MLP) have been applied to predict the number of cancers of Erbil and Duhok. Various related methods gather data according to specific regions, whereas in this work, data has been gathered from 2 cities which has 16 zones. GraphPad Prism version 8 (GraphPad Software, Inc.) was used for data analysis and presentation.

\section{Results}

Incidence of cancer in the Erbil and Duhok governorates stratified by sex

The total number and incidence for all cancer types in both Erbil and Duhok governorates was classified based on sex (Table 1). In Erbil, the number of female patients with cancer between 2013 and 2019 was higher than the number of male patients. The results showed a similar pattern in the Duhok governorate, as the number of female patients was higher than the number of male patients between 2013 and 2019, with the exception of 2014, where there were more cases of cancer amongst males.

Regardless of the sex of the patients, the number of total patients with cancer increased in both governorates with time. In 2013 in Erbil, there were 73 cases/100,000 individuals, and this figure increased by over $2 \mathrm{x}$ in the assessed time period to 174 cases/100,000 individuals. Similarly, in Duhok, the total number of patients increased by $>2 x$ between 2013 and 2019 from 486 (36 cases/100,000 individuals) in 2013 to 1,365 (85 cases/100,000 individuals) in 2019.

Obtained results illustrate that the proposed neural network algorithms optimize the error better than the statistical methods for the dataset for cancer collected from (2013-2019) from KRG Ministry of Health. Based on the current analysis, the number of cases of cancer are expected to increase by $>2 x$ in the next decade, with the line steeply increasing from 3457 cases in 2019 to 4,547 and 4,449 cases in 2028 based on LSTM and bi-LTSM analysis in the Erbil governorate, respectively. 
Table 1. Cancer Incidence in Erbil and Duhok Governorates Stratified Based on Gender

\begin{tabular}{lcccccc}
\hline & & Erbil & & Duhok \\
& Female & Male & Total & Female & Male & Total \\
\hline 2013 & $675(80)$ & $574(66)$ & $1250(73)$ & $252(38)$ & $234(35)$ & $486(36)$ \\
2014 & $995(114)$ & $761(86)$ & $1756(100)$ & $547(79)$ & $558(81)$ & $1105(80)$ \\
2015 & $962(108)$ & $776(85)$ & $1738(96)$ & $529(75)$ & $520(73)$ & $1049(74)$ \\
2016 & $936(102)$ & $773(83)$ & $1709(92)$ & $555(76)$ & $527(72)$ & $1082(74)$ \\
2017 & $1481(158)$ & $1305(136)$ & $2786(147)$ & $576(76)$ & $520(69)$ & $1096(72)$ \\
2018 & $1623(169)$ & $1420(145)$ & $3043(157)$ & $592(76)$ & $555(71)$ & $1147(74)$ \\
2019 & $1884(192)$ & $1573(157)$ & $3457(174)$ & $747(93)$ & $618(77)$ & $1365(85)$ \\
Total & 8492 & 7247 & 15739 & 3798 & 3532 & 7330 \\
Increasing ratio (2013 to 2019) & 2.4 fold & 2.37 fold & 2.38 fold & 2.44 fold & 2.2 fold & 2.36 fold \\
Female to Male ratio & & 1.17 & & & 1.07 & \\
\hline
\end{tabular}

In the Duhok governorate, the number of cancer cases is predicted to be 2,633 and 2,737 cases in 2028 based on LSTM and bi-LTSM analysis, compared to 1,365 cases in 2019, respectively (Figure 1).

Breast and LC were the most prominent types of cancer between 2013 and 2019 in the Erbil and Duhok governorates. The incidence of types of cancer per 100,000 population and all the registered cancer types for both sexes for the seven consecutive years (2013-2019) are presented in Table 2 and Figure 2, as well as in supplementary Tables 1 and 2. In the Erbil governorate, starting from 2013, the most prominent cancer type in females was BC, whereas for males, LC was the leading type. The second most common cancer type in females and males were haematological cancers, respectively. Regarding the Duhok governorate, the leading cancer types were $\mathrm{BC}$ and haematological cancers in females, and LC and haematological cancers in males.

Concerning 2014, in the Erbil governorate, for females, BC was again the most common type of cancer, followed by haematological cancers. However, for males, the most diagnosed type of cancers were haematological cancers followed by LC, respectively. In the Duhok governorate, a comparable pattern was observed concerning the top cancer types amongst females, with breast and haematological cancers accounting for the first and second most diagnosed types of cancer. LC, followed by haematological cancers, were the most diagnosed types of cancers amongst males.

In the Erbil governorate in 2015, the most common type of cancers amongst female patients were breast, followed by haematological cancers, whereas in male patients, the most diagnosed types of cancer were lung and haematological cancers. In Duhok, BC and skin cancer (SC) were the most commonly diagnosed types of cancer amongst females, whereas in males, LC, blood and SC were the most common types of cancers. Between 2016 and 2019, in the Erbil governorate the most common types of cancers amongst females were $\mathrm{BC}$ followed by CRC in 2016; haematological cancers in 2017; SC in 2018; and CRC in 2019. In Duhok, BC was the most diagnosed type of cancer in women between 2016 and 2019. The second most common types of cancers were haematological cancers in 2016, and SC from 2017-2019 in women. In male patients in both the Erbil and Duhok governorates, the most common types of cancer were LC
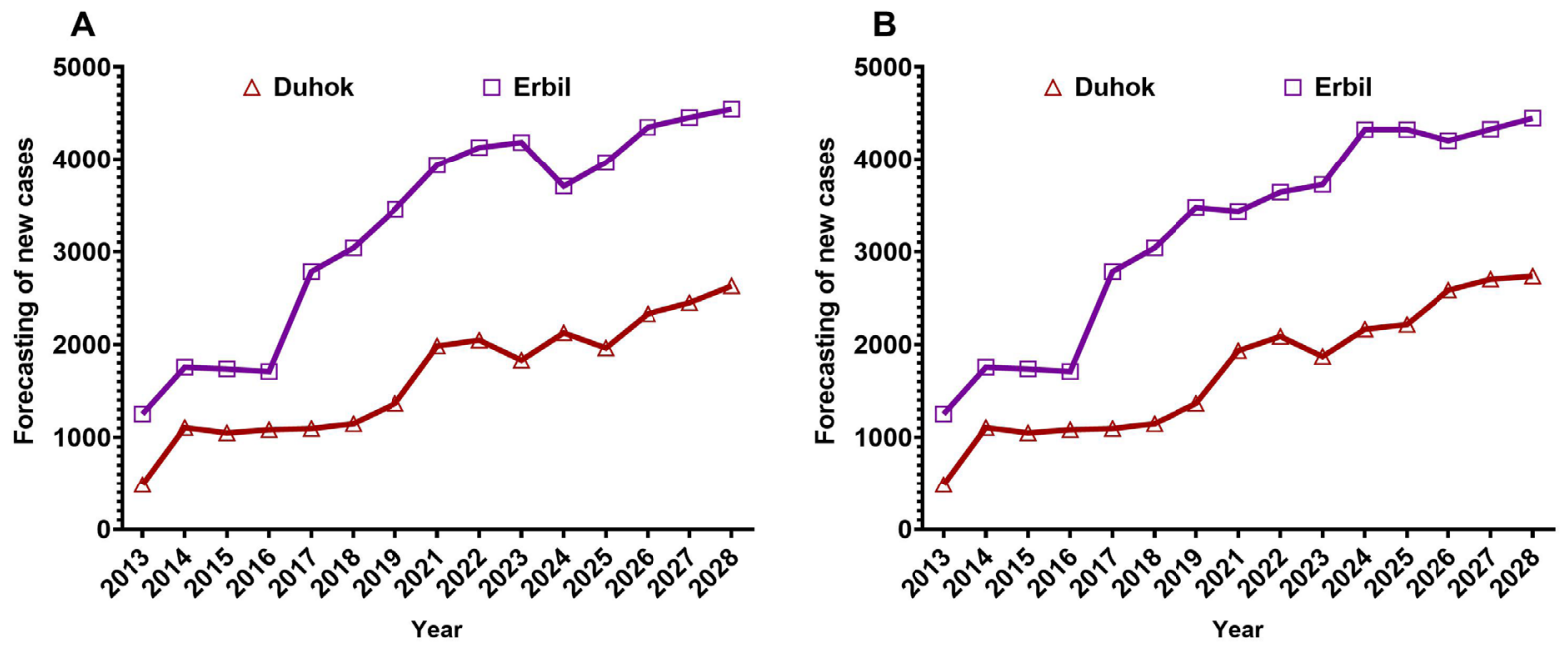

Figure 1. Projection of New Cases in Erbil and Duhok Governorates. A. LSTM and B. bi-LTSM neural network for prediction cancer in Erbil and Duhok governorates. 
Table 2. Incidence of Types of Cancer Per 100,000 Population in Erbil and Duhok Governorates

\begin{tabular}{|c|c|c|c|c|c|c|c|c|}
\hline & \multicolumn{4}{|c|}{ Erbil } & \multicolumn{4}{|c|}{ Duhok } \\
\hline & \multicolumn{2}{|c|}{ Male } & \multicolumn{2}{|c|}{ Female } & \multicolumn{2}{|c|}{ Male } & \multicolumn{2}{|c|}{ Female } \\
\hline & Total & per 100,000 & Total & per100,000 & Total & per 100,000 & Total & per 100,000 \\
\hline Breast & 105 & 1.2 & 3406 & 39.4 & 17 & 0.3 & 1205 & 18.1 \\
\hline Lung & 1264 & 14.4 & 344 & 4 & 649 & 9.7 & 98 & 1.5 \\
\hline Blood & 815 & 9.3 & 600 & 6.9 & 405 & 6.1 & 350 & 5.3 \\
\hline Colorectal & 641 & 7.3 & 550 & 6.4 & 319 & 4.8 & 263 & 4 \\
\hline Kidney & 814 & 9.3 & 286 & 3.3 & 369 & 5.5 & 117 & 1.8 \\
\hline Skin & 388 & 4.4 & 400 & 4.6 & 324 & 4.9 & 323 & 4.9 \\
\hline Prostate & 721 & 8.2 & & & 178 & 2.7 & & \\
\hline Lymph Nodes & 383 & 4.4 & 286 & 3.3 & 144 & 2.2 & 123 & 1.9 \\
\hline Stomach & 318 & 3.6 & 226 & 2.6 & 137 & 2.1 & 102 & 1.5 \\
\hline Brain & 252 & 2.9 & 199 & 2.3 & 170 & 2.6 & 153 & 2.3 \\
\hline Thyroid & 97 & 1.1 & 292 & 3.4 & 22 & 0.3 & 121 & 1.8 \\
\hline Ovary & & & 344 & 4 & & & 172 & 2.6 \\
\hline Uterus & & & 340 & 3.9 & & & 112 & 1.7 \\
\hline Bone & 149 & 1.7 & 119 & 1.4 & 74 & 1.1 & 49 & 0.7 \\
\hline Liver & 149 & 1.7 & 115 & 1.3 & 108 & 1.6 & 71 & 1.1 \\
\hline Pancreas & 141 & 1.6 & 115 & 1.3 & 80 & 1.2 & 60 & 0.9 \\
\hline Mouth & 142 & 1.6 & 102 & 1.2 & 20 & 0.3 & 20 & 0.3 \\
\hline Soft Tissues & 104 & 1.2 & 92 & 1.1 & 196 & 2.9 & 179 & 2.7 \\
\hline Esophagus & 69 & 0.8 & 69 & 0.8 & 38 & 0.6 & 23 & 0.3 \\
\hline Cervix and vagina & & & 132 & 1.5 & & & 51 & 0.8 \\
\hline Testis & 130 & 1.5 & & & 75 & 1.1 & & \\
\hline Pharynx & 65 & 0.7 & 33 & 0.4 & 15 & 0.2 & 7 & 0.1 \\
\hline Adrenal Gland & 31 & 0.4 & 31 & 0.4 & 2 & 0 & 7 & 0.1 \\
\hline Small Intestine & 39 & 0.4 & 19 & 0.2 & 5 & 0.1 & 1 & 0 \\
\hline Placenta & & & 57 & 0.7 & & & 2 & 0 \\
\hline Eye & 19 & 0.2 & 26 & 0.3 & 10 & 0.2 & 8 & 0.1 \\
\hline GIT-other & 16 & 0.2 & 15 & 0.2 & 39 & 0.6 & 43 & 0.6 \\
\hline Heart & 18 & 0.2 & 10 & 0.1 & 19 & 0.3 & 15 & 0.2 \\
\hline Peritoneum & 12 & 0.1 & 16 & 0.2 & 1 & 0 & 4 & 0.1 \\
\hline Glands - Other & 6 & 0.1 & 18 & 0.2 & 2 & 0 & 2 & 0 \\
\hline Nerves & 5 & 0.1 & 16 & 0.2 & 2 & 0 & 5 & 0.1 \\
\hline Ear/Nose & 13 & 0.1 & 4 & 0 & 48 & 0.7 & 43 & 0.6 \\
\hline Thymus & 6 & 0.1 & 9 & 0.1 & 1 & 0 & 1 & 0 \\
\hline NOS & 55 & 0.6 & 34 & 0.4 & 3 & 0 & 1 & 0 \\
\hline UPS & 217 & 2.5 & 250 & 2.9 & 60 & 0.9 & 67 & 1 \\
\hline
\end{tabular}

between 2016 and 2019, and the second most frequently diagnosed types of cancer were blood and kidney cancer (KC) in 2016-2019, and CRC in 2019.

Age-standardized incidence of cancer types in the Erbil and Duhok governorates

Over the 7-year period, in Erbil 15,739 cases of cancer were diagnosed (8,492 females and 7,247 males), and in Duhok 7,330 cases of cancer were diagnosed (3,798 females and 3,532 males). The overall incidence for both sexes combined per 100,000 individuals was $123.3(131.5$ for females and 109.38 for males) in Erbil; and 71.3 (74.86 for females and 67.86 for males) in Duhok.
Although the overall female-to-male cancer ratio was 1.2 and 1.1 for Erbil and Duhok, respectively, there were differences in the average age-standardized incidence rate (ASIR) between sexes based on the age groups. For example, the ASIR for males was slightly higher than that for females, in children (aged 0-14 years) in both Erbil and Duhok (Figure 3), whereas it was similar in both sexes in the adolescent (aged 15-19 years). For patients aged 20-59 years, ASIRs were higher for females than males in both governorates. The gap was highest in the age groups 30-39 and $40-49$ years, where the rate in females was $>2 x$ higher than that of males in both Erbil and Duhok. For patients with cancer aged $>60$ years, ASIRs were higher in males 


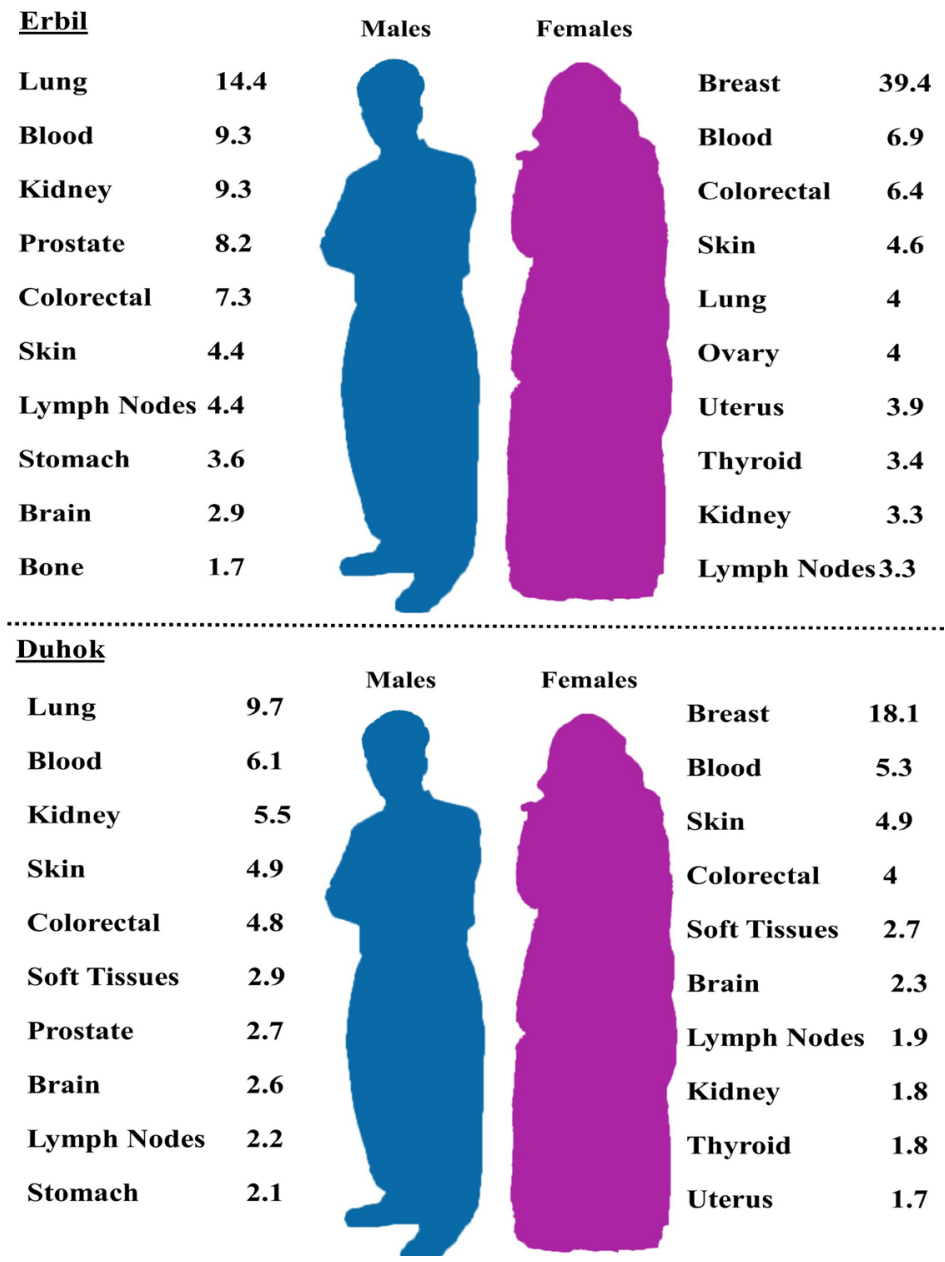

Figure 2. Top Ten Prevalent Cancer Types Based on Sex in Erbil and Duhok Governorates Shows the Most Common Types of Cancer in Both Sexes and in Both Governorates Per 100,000 Population of the Same Sex. In male patients, LC accounted for 14.4 cases/100,000 followed by blood and kidney 9.3 cases/100,000 in Erbil governorate. Comparably, in Duhok governorate, the most common type of cancer was LC corresponding to 9.7 cases $/ 100,000$ cases followed by blood cancer 6.1 and KC 5.5 cases/100,000. However, concerning female patients, BC and blood cancers were the top cancers in both governorates.
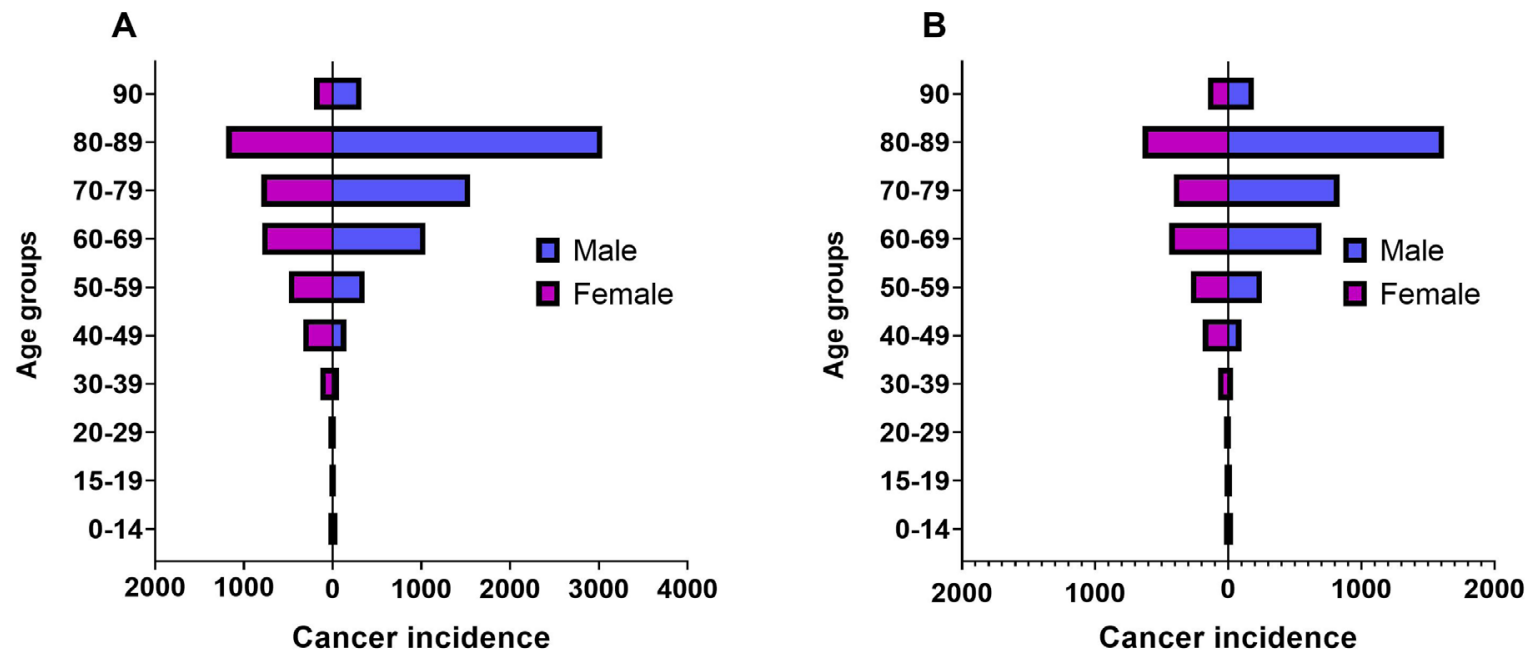

Figure 3. Cancer Incidence Based on Sex and Age Groups in Erbil and Duhok Governorates, Illustrates the Number of Cancer Patients According to Their Age Groups in Both Governorates throughout 2013 to 2019. The maximum number of cancer patients in Erbil governorate was in the age group of 61-70. In Duhok governorate, the maximum number of cancer patients were also in the age group of 61-70 from 2014-2019 except for 2015 where the maximum number of cancer patients were aged between 51-60 years. 


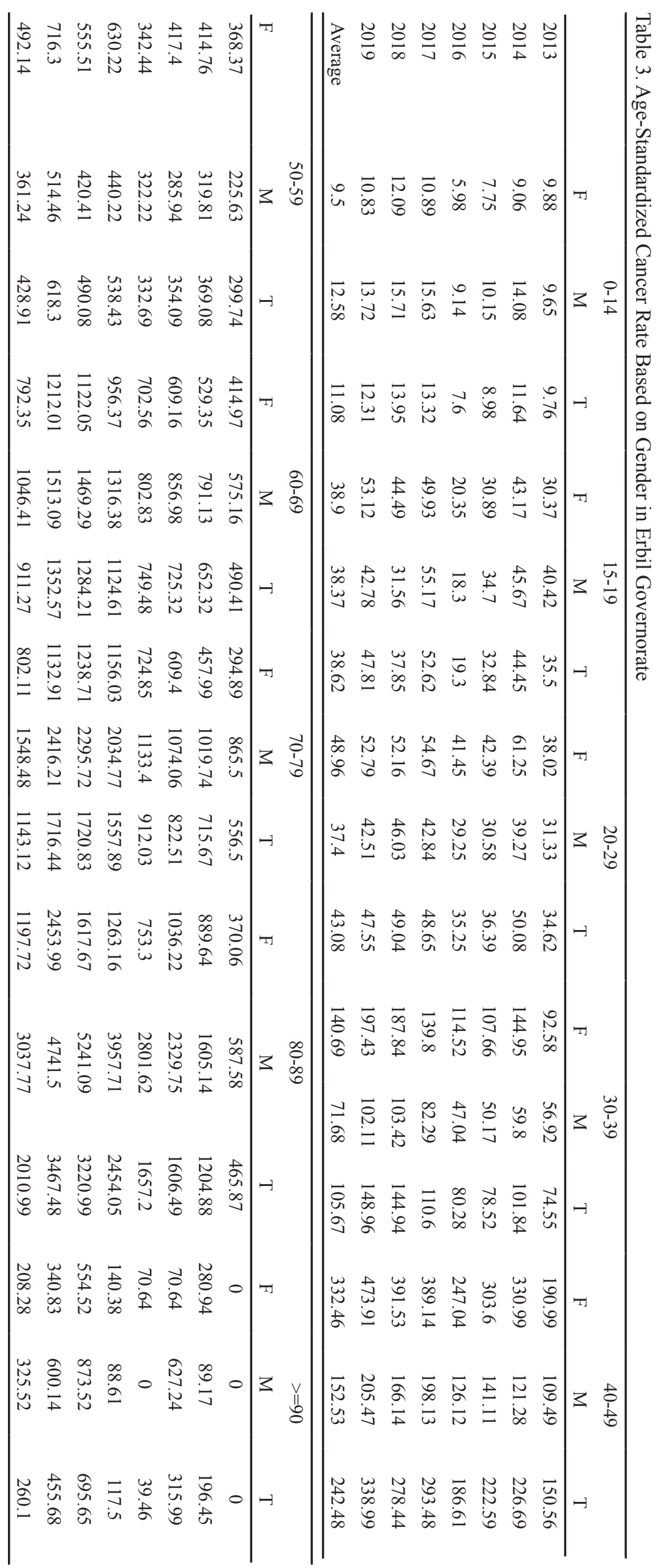


than in females, and were $>2 \mathrm{x}$ higher in the age groups 70-79 and 80-89 years in both governorates. In summary, in the early ages of life ( $<20$ years), male cancer incidence was higher, whereas the female cancer incidence started to increase afterwards until the age of 60 years old, after which male cancer incidence increased markedly.

Except for a minor decrease in ASIR in the age group of $15-19$ (27.46) years to the age group of 20-29 (26.65) years in the Duhok governorate, overall average ASIR increased with age. Average ASIRs per 100,000 individuals by age groups in Erbil and Duhok were as follows (respectively): 0-14 (11.08 and 8.17), 15-19 (38.62 and 27.46), 20-29 (43.08 and 26.65) and 30-39 (105.67 and 56.88) years. The peak ASIR was recorded in the age group 80-90 years, which was 2,010.99 cases/100,000 individuals in Erbil and 1,074.32 cases/100,000 individuals in Duhok. By contrast, a marked decrease was recorded in patients aged $\geq 90$ for both governorates (Tables 3 and 4).

The median age of cancer incidence was 55 years for both governorates. In total, $>50 \%$ of the cancer cases were registered in patients aged $>50$ years; $58.1 \%$ in Erbil and $57.4 \%$ in Duhok. The highest percentage of cases were recorded for patients aged 60-70 years; 22.8 and $22.3 \%$ for Erbil and Duhok, respectively. The percentages of registered cases in children (0-14) were $3.9 \%$ in Erbil and $4.8 \%$ in Duhok, and in patients aged $15-19$ years, they were 6\% in Erbil and 6.2\% in Duhok. Overall, for cancer patients $<20$ years old, the percentage of recorded cases accounted for 7.2\% in Erbil and 8.8\% in the Duhok governorate.

Common cancer types differed between age groups (Table 5). For example, haematological cancers was the most common type of cancer amongst children (0-14 years) and adolescents (15-19 years) in Erbil (4.59 vs. 11.55 cases $/ 100,000$ individuals) and Duhok (3.52 vs. 9.25 cases $/ 100,000$ individuals). Combining these two age groups, haematological cancers was followed as the most common type of cancer in Erbil by lymph node cancer (7.45 cases/100,000 individuals) and brain tumours (4.13 cases/100,000 individuals); and in Duhok by lymph node cancer (4.35 cases/100,000 individuals) and soft tissue cancer ( 3.86 cases $/ 100,000$ individuals). In young adults aged 20-29 years, both haematological cancers $(6.18$ cases/100,000 individuals) and BC (6.18 cases/100,000 individuals) were the most commonly registered types of cancers in Erbil, whereas in Duhok, BC was the most common type, followed by lymph node and KC. In Duhok the highest prevalence was for haematological cancers (3.1 cases/100,000 individuals), CRC (2.4 cases/100,000 individuals) and lymph node cancer (2.23 cases/100,000 individuals). The most common types of cancer in the age groups 30-39, 40-49 and 50-59 years, was BC for both provinces, whereas for the age groups 70-79 and 80-89 years it was LC. Stomach cancer (50.11 cases/100,000 individuals) and SC (28.52 cases/100,000 individuals) were the most common types of cancer diagnosed amongst the most elderly patients ( $\geq 90$ years) in Erbil and Duhok, respectively.

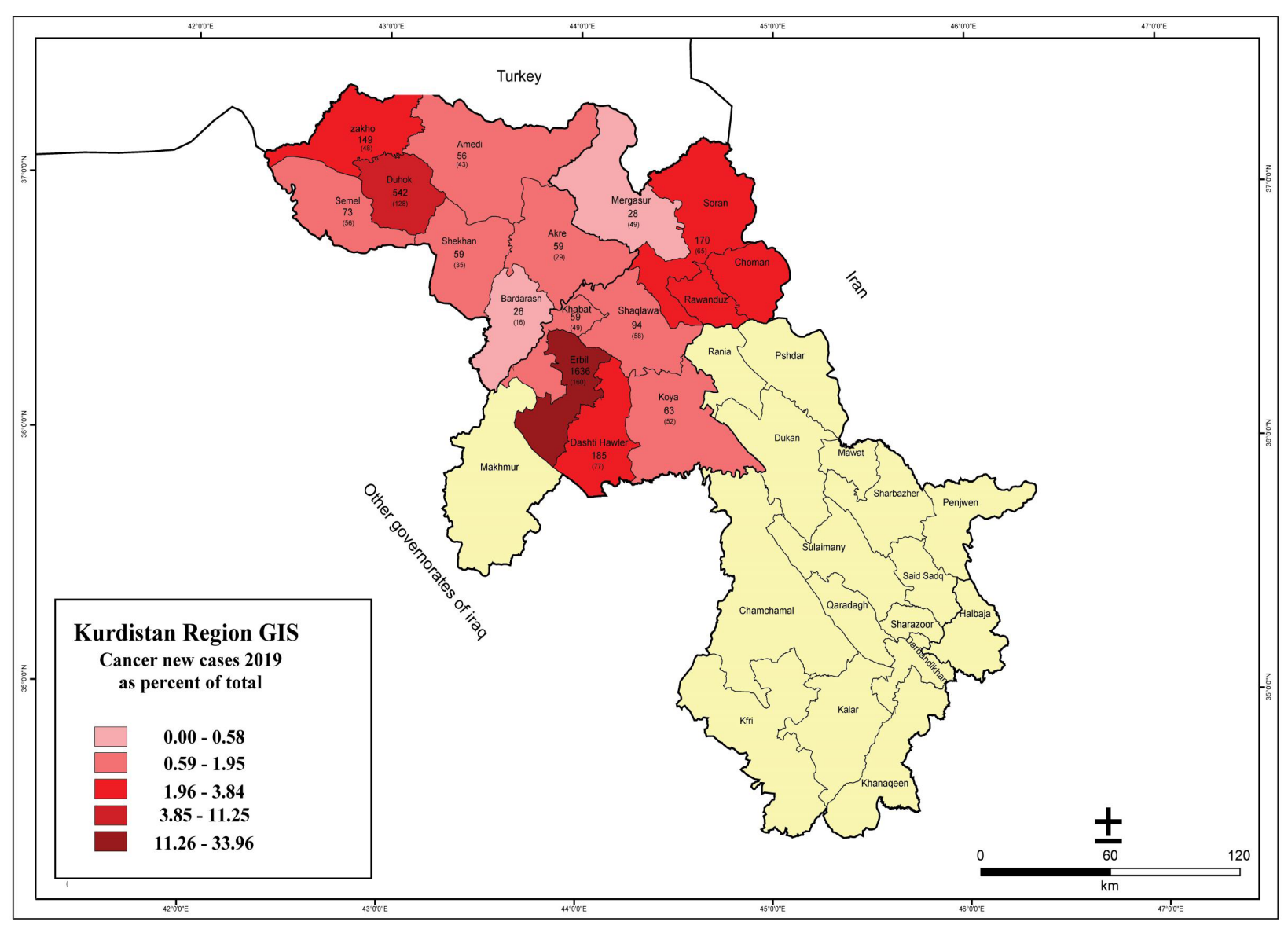

Figure 4. Kurdistan Region Map of Cancer Incidence Displaying Geographic Distribution of Cancer in Erbil and Duhok Governorates 


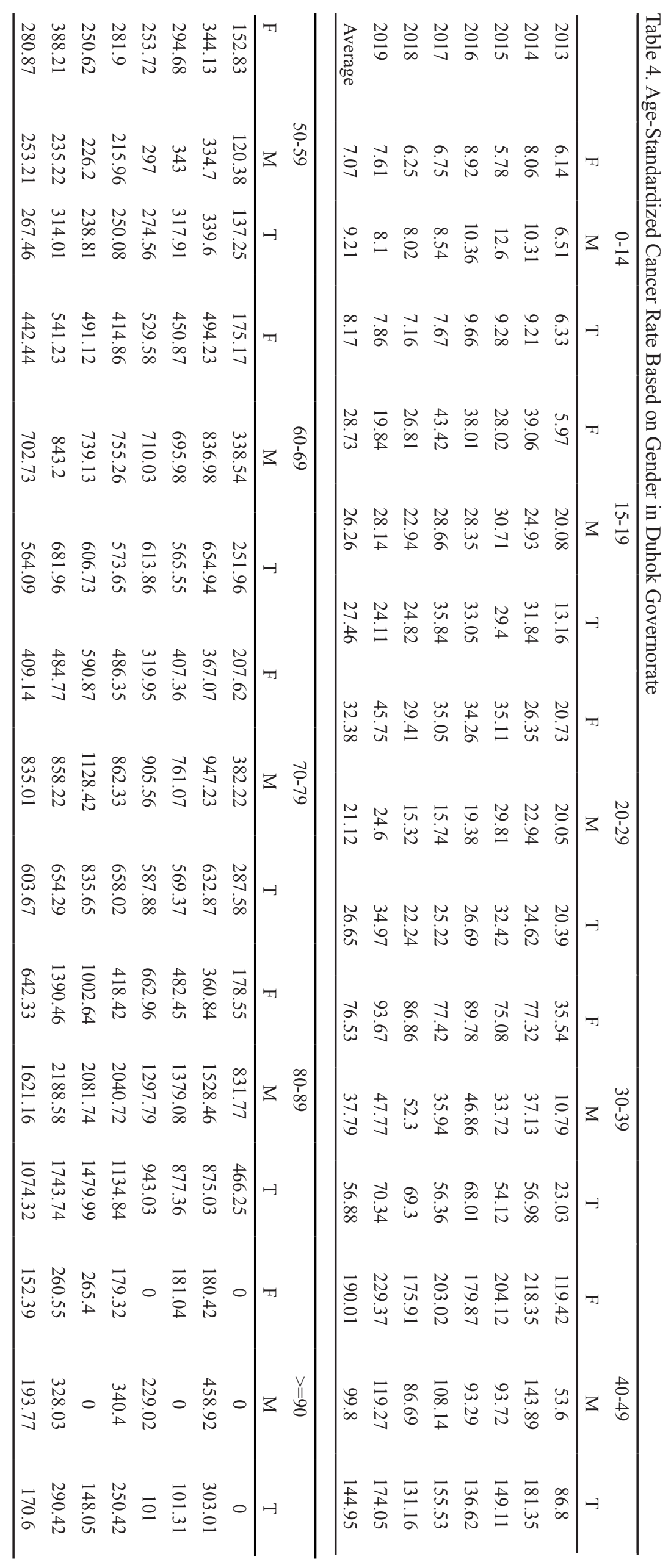


Table 5. Age-Standardized Rate of Cancer Types in Erbil and Duhok

\begin{tabular}{|c|c|c|c|c|c|c|c|c|c|c|c|}
\hline & \multicolumn{11}{|c|}{ Erbil } \\
\hline & $0-14$ & $15-19$ & $20-29$ & $30-39$ & $40-49$ & $50-59$ & $60-69$ & $70-79$ & $80-89$ & $>=90$ & Average \\
\hline Breast & 0 & 0.3 & 6.18 & 37.08 & 99.23 & 122.39 & 147.54 & 111.14 & 141.04 & 22.27 & 68.72 \\
\hline Lung & 0 & 0.22 & 0.55 & 2.6 & 11.21 & 45.81 & 171 & 215.46 & 348.9 & 22.27 & 81.8 \\
\hline Blood & 4.59 & 11.55 & 6.18 & 7.8 & 15.1 & 27.51 & 59.43 & 72.65 & 126.2 & 11.14 & 34.21 \\
\hline Colorectal & 0.05 & 0.82 & 3.92 & 8.48 & 19.25 & 36.73 & 73.25 & 100.59 & 122.49 & 11.14 & 37.67 \\
\hline Kidney & 1.14 & 0.6 & 1.24 & 4.4 & 13.24 & 36.02 & 74.29 & 114.87 & 193.01 & 27.84 & 46.66 \\
\hline Skin & 0.04 & 0.22 & 0.6 & 3.84 & 8.83 & 21.13 & 59.17 & 95 & 270.95 & 33.41 & 49.32 \\
\hline Prostate & 0 & 0 & 0.09 & 0.12 & 0.97 & 12.91 & 72.21 & 153.99 & 300.65 & 50.11 & 59.1 \\
\hline Lymph nodes & 0.89 & 6.56 & 5.76 & 6.81 & 6.62 & 11.91 & 22.42 & 23.59 & 48.25 & 5.57 & 13.84 \\
\hline Stomach & 0.05 & 0.3 & 0.92 & 2.91 & 9 & 13.05 & 41.45 & 52.78 & 107.64 & 16.7 & 24.48 \\
\hline \multirow[t]{3}{*}{ Brain } & 0.85 & 3.28 & 2.4 & 4.77 & 7.68 & 10.07 & 13.56 & 11.18 & 11.14 & 0 & 6.49 \\
\hline & \multicolumn{11}{|c|}{ Duhok } \\
\hline & $0-14$ & $15-19$ & $20-29$ & $30-39$ & $40-49$ & $50-59$ & $60-69$ & $70-79$ & $80-89$ & $>=90$ & Average \\
\hline Breast & & 0.19 & 3.63 & 18.86 & 43.67 & 53.1 & 57.89 & 43.83 & 47.53 & 14.26 & 28.3 \\
\hline Blood & 3.52 & 9.25 & 3.1 & 5.05 & 9.82 & 20.73 & 37.48 & 45.42 & 76.05 & 7.13 & 21.75 \\
\hline Lung & & 0.09 & 0.35 & 1.26 & 8.13 & 30.91 & 105.41 & 105.99 & 156.84 & 7.13 & 41.61 \\
\hline Skin & 0.09 & 1.13 & 1.87 & 3.94 & 10.27 & 25.64 & 62.58 & 78.89 & 128.33 & 28.52 & 34.13 \\
\hline Colorectal & & 0.76 & 2.4 & 4.26 & 14.11 & 21.82 & 52.54 & 47.81 & 76.05 & 7.13 & 22.69 \\
\hline Kidney & 0.57 & 0.66 & 0.76 & 1.97 & 8.35 & 20.18 & 48.86 & 49.41 & 104.56 & 7.13 & 24.25 \\
\hline Soft tissues & 0.83 & 2.93 & 1.99 & 3.08 & 6.66 & 10.36 & 25.77 & 23.11 & 61.79 & & 13.65 \\
\hline Brain & 1.61 & 1.89 & 1.87 & 2.52 & 5.19 & 9.09 & 17.4 & 15.14 & 4.75 & 7.13 & 6.66 \\
\hline Lymph nodes & 0.57 & 3.78 & 2.23 & 2.45 & 3.84 & 8 & 11.04 & 11.95 & 33.27 & & 7.71 \\
\hline Stomach & & 0.09 & 0.59 & 1.66 & 3.84 & 10 & 24.09 & 27.89 & 52.28 & & 12.04 \\
\hline
\end{tabular}

Percentage of patients with cancer by grade at the time of cancer detection

The number of registered patients in each year and the percentage of grades of cancer relative to the total number of patients in each year are summarized in Table 6. In the Erbil governorate, the majority of patients between 2013 and 2019 had their cancer detected with their cancer grades unknown except for 2016, where the

Table 6. Cancer Grades of Patients at the First time of Detection (Percentage of the Grade Comparing to Total no. of Patients of That Year)

\begin{tabular}{|c|c|c|c|c|c|c|c|c|c|}
\hline & & & & & Erbil & & & & \\
\hline & B-cell & Grade I & Grade II & Grade III & Grade IV & NK cell & Null cell & T-cell & Unknown \\
\hline 2013 & 49 (3.92) & $26(2.08)$ & $204(16.32)$ & $189(15.12)$ & $35(2.8)$ & & $2(0.16)$ & $6(0.48)$ & $739(59.12)$ \\
\hline 2014 & $42(2.39)$ & $48(2.73)$ & $393(22.38)$ & $330(18.79)$ & $57(3.25)$ & $2(0.11)$ & & $6(0.34)$ & $878(50)$ \\
\hline 2015 & $53(3.05)$ & $67(3.86)$ & 367 (21.12) & $280(16.11)$ & $105(6.04)$ & & $1(0.06)$ & $9(0.52)$ & $856(49.25)$ \\
\hline 2016 & $31(1.81)$ & $113(6.61)$ & $564(33)$ & $405(23.7)$ & $135(7.9)$ & & $1(0.06)$ & $11(0.64)$ & $449(26.27)$ \\
\hline 2017 & 47 (1.69) & $194(6.96)$ & 867 (31.12) & $565(20.28)$ & 206 (7.39) & $2(0.07)$ & & $8(0.29)$ & 897 (32.2) \\
\hline 2018 & $51(1.68)$ & $253(8.31)$ & $904(29.71)$ & $539(17.71)$ & $241(7.92)$ & $1(0.03)$ & & $9(0.3)$ & $1045(34.34)$ \\
\hline 2019 & $47(1.36)$ & $271(7.84)$ & 1009 (29.19) & 649 (18.77) & $242(7.00)$ & $1(0.03)$ & & $3(0.09)$ & $1235(35.72)$ \\
\hline \multirow[t]{3}{*}{ Total } & $320(2.03)$ & $972(6.18)$ & $4308(27.37)$ & 2957 (18.79) & $1021(6.49)$ & $6(0.04)$ & $4(0.03)$ & $52(0.33)$ & $6099(38.75)$ \\
\hline & & & & & Duhok & & & & \\
\hline & B-cell & Grade I & Grade II & Grade III & Grade IV & NK cell & Null cell & T-cell & Unknown \\
\hline 2013 & $6(1.23)$ & & & $1(0.21)$ & & & $49(10.08)$ & & $430(88.48)$ \\
\hline 2014 & $2(0.18)$ & & & $1(0.09)$ & & $30(2.71)$ & $147(13.3)$ & & $925(83.71)$ \\
\hline 2015 & $4(0.38)$ & & & & & $30(2.86)$ & 93 (8.87) & & $922(87.89)$ \\
\hline 2016 & $6(0.55)$ & & & $5(0.46)$ & $2(0.18)$ & $53(4.9)$ & $76(7.02)$ & $1(0.09)$ & 939 (86.78) \\
\hline 2017 & $4(0.36)$ & & $1(0.09)$ & $7(0.64)$ & & $52(4.74)$ & $104(9.49)$ & & 928 (84.67) \\
\hline 2018 & $13(1.13)$ & $2(0.17)$ & $13(1.13)$ & $82(7.15)$ & $4(0.35)$ & $62(5.41)$ & $83(7.24)$ & & $888(77.42)$ \\
\hline 2019 & $17(1.25)$ & $8(0.59)$ & $26(1.9)$ & $61(4.47)$ & $8(0.59)$ & $41(3)$ & $110(8.06)$ & $1(0.07)$ & $1093(80.07)$ \\
\hline Total & $52(0.71)$ & $10(0.14)$ & $40(0.55)$ & $157(2.14)$ & $14(0.19)$ & $268(3.66)$ & $662(9.03)$ & $2(0.03)$ & $6125(83.56)$ \\
\hline
\end{tabular}


Table 7. Stratification of Cancer Incidence in Erbil City Based on Zones

\begin{tabular}{|c|c|c|c|c|c|c|c|c|c|}
\hline & 2013 & 2014 & 2015 & 2016 & 2017 & 2018 & 2019 & Total & $\%$ \\
\hline \multirow[t]{2}{*}{ Erbil Center } & 561 & 678 & 726 & 821 & 1300 & 1522 & 1636 & 7244 & 46 \\
\hline & 64 & 75 & 78 & 86 & 133 & 152 & 160 & & \\
\hline \multirow[t]{2}{*}{ Deshti Erbil } & 76 & 129 & 94 & 101 & 168 & 194 & 185 & 947 & 6 \\
\hline & 37 & 61 & 43 & 45 & 73 & 83 & 77 & & \\
\hline \multirow[t]{2}{*}{ Sooran, Rawandooz, Choman } & 61 & 76 & 85 & 87 & 127 & 140 & 170 & 746 & 5 \\
\hline & 27 & 33 & 36 & 36 & 51 & 55 & 65 & & \\
\hline \multirow[t]{2}{*}{ Shaqlawa, Hareer, Salahaddin } & 31 & 45 & 64 & 73 & 91 & 108 & 94 & 506 & 3 \\
\hline & 22 & 31 & 43 & 48 & 59 & 68 & 58 & & \\
\hline \multirow[t]{2}{*}{ Kweisengek } & 25 & 38 & 43 & 46 & 46 & 59 & 63 & 320 & 2 \\
\hline & 24 & 35 & 39 & 41 & 40 & 50 & 52 & & \\
\hline \multirow[t]{2}{*}{ Khabat } & 22 & 20 & 34 & 33 & 56 & 68 & 59 & 292 & 2 \\
\hline & 21 & 19 & 31 & 30 & 49 & 58 & 49 & & \\
\hline \multirow[t]{2}{*}{ Meirgehsor } & 7 & 13 & 14 & 14 & 23 & 22 & 28 & 121 & 1 \\
\hline & 14 & 26 & 27 & 26 & 42 & 39 & 49 & & \\
\hline Other cities & 467 & 757 & 678 & 534 & 975 & 930 & 1222 & 5563 & 35 \\
\hline
\end{tabular}

highest percentage (33\%) of cases had grade II cancer at the time of detection. However, in the Duhok governorate, the majority of patients had unknown grades of cancer between 2013 and 2019.

Table 7 and Figure 4 demonstrate the stratification of patients with cancer based on governorate zones. Erbil governorate had the most patients with cancer, and the number increased from 64 cases/100,000 individuals in 2013 to 160 cases/100,000 individuals in 2019. Meirgehsor had the lowest number of cases/100,000 individuals compared with other zones in the Erbil governorate between 2013 and 2019, except for 2014 where Khabat registered the lowest number (19 cases/100,000 individuals). Duhok centre had the highest number of patients compared with the other zones of the Duhok governorate. For example, in 2019, 128 cases/100,000 individuals were recorded in Duhok centre compared with only 16 cases/100,000 individuals in Berdehresh
(Table 8; Figure 4).

\section{Discussion}

The present study reported the cancer incidence trends between 2013 and 2019 and predicted the increasing trend for the next decade. The overall cancer incidence rate increased sharply during 2013 and 2014 in both the Erbil and Duhok governorates. A plausible explanation for this increase could be due to the demographical changes in the Erbil population as a result of the ISIS invasion of Mosul governorate in 2014, which caused thousands of internally displaced individuals to migrate to a Khazer refugee camp in Erbil, which led to the detection of a further increase in cancer cases and incidences. Thus far, previous studies focused on risk factors that directly influence the incidence rate of cancer diseases in Iraq, such as the consequences of various wars, changes in lifestyle (Hussain and Habib,

Table 8. Stratification of Cancer Incidence in Duhok City Based on Zones

\begin{tabular}{|c|c|c|c|c|c|c|c|c|c|}
\hline & 2013 & 2014 & 2015 & 2016 & 2017 & 2018 & 2019 & Total & $\%$ \\
\hline \multirow[t]{2}{*}{ Duhok Center } & 239 & 571 & 580 & 542 & 495 & 536 & 542 & 3505 & 48 \\
\hline & 68 & 157 & 155 & 140 & 124 & 131 & 128 & & \\
\hline \multirow[t]{2}{*}{ Zakho } & 63 & 137 & 114 & 139 & 110 & 137 & 149 & 849 & 12 \\
\hline & 24 & 51 & 41 & 49 & 38 & 45 & 48 & & \\
\hline \multirow[t]{2}{*}{ Sumail } & 10 & 31 & 38 & 48 & 36 & 39 & 73 & 275 & 4 \\
\hline & 9 & 28 & 33 & 40 & 29 & 31 & 56 & & \\
\hline \multirow[t]{2}{*}{ Ammadyia } & 2 & 13 & 7 & 10 & 53 & 52 & 56 & 193 & 3 \\
\hline & 2 & 12 & 6 & 8 & 43 & 41 & 43 & & \\
\hline \multirow[t]{2}{*}{ Aqreh } & & & & 1 & 40 & 65 & 59 & 165 & 2 \\
\hline & & & & 1 & 21 & 33 & 29 & & \\
\hline \multirow[t]{2}{*}{ Shaikhan } & & & & 5 & 50 & 39 & 59 & 153 & 2 \\
\hline & & & & 3 & 32 & 24 & 35 & & \\
\hline \multirow[t]{2}{*}{ Berdehresh } & & & & 8 & 21 & 15 & 26 & 70 & 1 \\
\hline & & & & 5 & 14 & 10 & 16 & & \\
\hline Other cities & 172 & 353 & 310 & 329 & 291 & 264 & 401 & 2120 & 29 \\
\hline
\end{tabular}


2015), economic disease burden (Yabroff et al., 2011), economic crises (Alwan, 2016), social status (Merletti et al., 2011), environmental pollution and exposure to carcinogenic agents. Moreover, some behavioural factors, such as smoking, alcohol consumption, drug abuse and fast-food consumption have recently been shown to significantly increase the risk of certain types of cancer in KRG (Huerta and Grey, 2007; Jemal et al., 2010; Merletti et al., 2011).

According to the prediction of the current study for the next decade, there will be a significant increase in cancer burden in the Erbil and Duhok governorates. This is in agreement with previous national studies on different types of cancer (Al-Hashimi and Wang, 2014; Museedi and Younis, 2014; Khoshnaw et al., 2015; Board, 2018), as well as international trends that estimated an increase of $28 \%$ globally between 2006 and 2016 (Fitzmaurice et al., 2019). Correspondingly, cancer incidence trends in less developed countries have been predicted to increase from $56 \%$ in 2008 to $>60 \%$ in 2020 . By contrast, in the US and several Western countries, the trends are generally expected to be decreasing (Jemal et al., 2010).

Cancer incidence rates for all cancer types increased in the KRG between 2013 and 2019, meanwhile in other parts of Iraq, the cancer rate increased from 44.58 to $67.86 / 100,000$ between 2008 and 2016, representing a more than $50 \%$ increase (Hussain and Lafta, 2021). Although, these rates were lower compared to neighbouring countries, or countries in Europe, East Asia and the US (Yazdani-charati et al.,2014), which is likely associated with the lack of implementing evidence-based cancer control programs and planning, which are fundamental for a high-quality cancer data registry, but which are almost totally unavailable (Ferlay et al., 2019) in most low- and middle-income countries, including in the KRG. The incidence and burden amongst both sexes between 2013 and 2019 saw a two-fold increase in Erbil and Duhok governorates for all cancer types. The reason for this drastic increase is likely due to various risk factors, including ageing, unhealthy lifestyles, insufficient physical activity, infectious agents, genetic mutations and environmental risk factors (Anton-Culver, 1995; Popkin, 2006; McAllister et al., 2009).

Nevertheless, the ratio of cancer rates in females was slightly higher compared with males in both the Erbil and Duhok governorates. A higher percentage of cancer rates in females is most likely due to the differences in endogenous hormones and exposure to indoor and outdoor pollutants, as well as the complex interactions between these individual factors (Siegel et al., 2020).

In the Erbil and Duhok governorates, the most frequently documented cancer amongst females was BC between 2013 and 2019, followed by haematological cancers, then CRC and LC. The most common cancer aligns with cancer incidence trends worldwide. However, the second, third and fourth most common cancer types in the world are CRC, lung and cervical uterine cancer, respectively (Bray et al., 2018). The most prominent risk factors of BC is sex (Rojas and Stuckey, 2016), followed by age, reproductive factors, a longer menstrual period, age of females at conception of their first child and increased use of oral contraceptives, particularly in Middle East countries, including Iraq (Anderson et al., 2014). The highest prevalence of female $\mathrm{BC}$ in Western countries is between the ages of 75-79 years, whereas in $\mathrm{KRG}$, it is between the ages of 51-60 years; this indicates that BC occurs in women in this population at a younger age, as in the neighbouring country of Iran, and unlike women in Western countries (Azizi et al., 2000; Anderson et al., 2014).

The most commonly diagnosed cancer in men is $\mathrm{LC}$ in Erbil and Duhok, and this aligns with the most diagnosed cancer type in the world. Globally, smoking is the leading cause of death amongst patients with LC, accounting for $\sim 80 \%$ of cancer-associated deaths amongst men (Azizi et al., 2000; Anderson et al., 2014). The reason behind the higher prevalence of LC in Duhok compared to the Erbil governorate could partially be caused by unventilated gasoline-fuelled stoves, indoor kerosene heaters and fumes from cooking (IARC, 2014). Another notable risk factor is the preponderance of tobacco smoking amongst women in this governorate. In Erbil, LC ranks fifth place for overall cancer rates in this area, which may indicate that women are smoking less than men, and are less exposed to outdoor industrial pollutions. However, LC rates amongst women is comparable to global LC incidence rates for 2018 (Charati et al., 2014).

The second most diagnosed cancer during the 7 years assessed in KRG is leukaemia, and the incidence was slightly higher in males than in females. Leukaemia is a relatively less commonly diagnosed cancer worldwide (Keum and Giovannucci, 2019), and the first leading cause of death in the Sulaymaniyah governorate of KRG between 2006 and 2013, as reported by Khoshnaw et al (Khoshnaw et al., 2015). It is likely that three major destructive wars in Iraq since 1980 have resulted in the presence of significant volumes of military pollution throughout Iraq, including depleted uranium (DU), which are widely suspected of causing a significant increase in congenital disabilities and cases of cancer, particularly childhood leukaemia (Hon et al., 2015; Alwan and Kerr, 2018).

In both governorates, the third most common cancer among men is $\mathrm{KC}$, for which incidence rates amongst men were nearly three to four times higher than amongst women in the Erbil governorate, and $>2 x$ higher in men compared with women in the Duhok governorate. Higher exposure to the contaminants of military warfare during the last three decades of the conflict in Iraq amongst men may explain the increased incidence of $\mathrm{KC}$ in this demographic. The kidney is considered to be the most susceptible target organ to DU toxicity (Hon et al., 2015). Studies have shown that renal cells damaged by DU toxicity can cause KC (McDiarmid et al., 2000). Cancer of the kidney is one of the top six most common types of cancer worldwide in 2018, with incidence rates of $\sim 2.2 \%$ of all cancer sites, and the leading cause of death, with $\sim 1.8 \%$ of cancer-associated deaths. Consequently, mortality and incidence rates of $\mathrm{KC}$ amongst men were $\sim 2 \mathrm{x}$ that observed in women (Bray et al., 2018).

Colorectal cancer was the third most common type of cancer amongst women and the fifth most common

Asian Pacific Journal of Cancer Prevention, Vol 23 
amongst men in the Erbil governorate between 2013 and 2019. It represented the fifth most prevalent type of cancer in the Duhok governorate for both sexes. The reasons for the burden of CRC in the KRG are considered to reflect the changes in lifestyle and dietary factors, including the increasing prevalence of smoking and obesity, which are associated with Westernized lifestyle factors (Center et al., 2009). In 2018, CRC was the second most prevalent cancer amongst women worldwide, and the third amongst men. Overall, CRC ranked third in prevalence, but second worldwide in mortality (Bray et al., 2018). Likewise, in neighbouring countries such as in Iran, CRC ranked the third most common type of cancer in 2015 (Esmaeimzadeh et al., 2015).

In the Duhok governorate, $\mathrm{SC}$ was the fourth most commonly diagnosed cancer amongst both sexes between 2013 and 2019. In the Erbil governorate it was amongst the top four most commonly diagnosed types of cancers, and the sixth most common cancer amongst men. Relative to other areas of Iraq, SC cases in the KRG are significantly higher, which can be linked to the geographical location and other lifestyle variables, such as the lack of use of sun blockers, excessive ultraviolet exposure, increased sun exposure times and occupancy (Surdu, 2014). In 2015, the Iraqi Cancer Registry declared SC as the ninth most common type of cancer in Iraq, and the incidence rates amongst males and females were $3.9 \%$ and $2.6 \%$, respectively (Board, 2018). Globally, in 2018, melanoma $\mathrm{SC}$ was the eighth and ninth most common SC in women and men, respectively, in High Development Index countries (Bray et al., 2018).

Prostate cancer (PC) ranked as the fourth most common type of cancer amongst men between 2013 and 2019 in the Erbil governorate, accounting for $\sim 10 \%$ of male cases, whereas in the Duhok governorate it was the seventh most frequently diagnosed cancer, accounting for $5 \%$ of male cases. PC is the second most widely diagnosed cancer in men, accounting for $13.5 \%$ of all cancer types worldwide; and the fifth-largest cause of cancer-associated death worldwide (Bray et al., 2018). The PC incidence rates in 2018 were $6.6 \%$ in Iraq, which is lower than in most neighbouring countries including Iran (16.6\%), Jordan (14.7\%), Kuwait (21.6\%), Syria (20.1\%) and Turkey (41.7\%); Saudi Arabia also has an incidence of $6.6 \%$ (Hassanipour-Azgomi et al., 2016). The variations in incidence rates could be due to differences in the testing methods for prostate-specific antigens (Baade et al., 2009).

The overall cancer incidence was higher in Erbil than in Duhok. One of the most important risk factors for cancer incidence is age (Smetana et al., 2016). In the present study, the median age (55 years) of cancer patients was similar to the results of other studies conducted in Middle Eastern countries, such as Jordan [55 years (Tarawneh et al., 2010) and 56 years (Abdel-Razeq et al., 2015)] and Palestine [55 years (Halahleh and Gale, 2018)], whereas cancer patients in the present study were generally $\sim 10$ years younger than in developed Western countries. The median age of cancer patients in Norway is 69 years (Larsen et al., 2015), and in the US it is 66 years (Howlader et al., 2020). This could be attributable to the Kurdish population and other nations in the Middle East having younger populations than Western countries.

The highest percentages of diagnosed cases reported in the present study were in Erbil $(23.3 \%)$ and Duhok $(22.8 \%)$ for patients aged between 60-69 years. This result was in line with previous reports finding $23.1 \%$ in Baghdad (Board, 2018) and 19.7\% in Basrah (Hussain and Habib, 2015), but differed from reports in neighbouring countries, where the age structure of the population is similar, such as in Jordan (23\%) (Khader et al., 2018). However, the highest incidence was found in patients aged $70-79$ years in some European countries, such as the UK with 28.34\% and Norway 27.7\% (Larsen et al., 2015).

Paediatric cancers amongst children (aged 0-14 years) and adolescents (aged 15-19 years) are relatively rare and have a distinct profile, but account for a higher percentage of cancer in developing countries than in developed countries, which is partly due to the younger age structure of developing countries, including Iraq. To the best of our knowledge, this is the first population-based study to estimate the ASIR and tumour profile in paediatric patients. The average ASIR of cancer in children per 100,000 individuals in the present study was 11.08 and 8.17 in Erbil and Duhok, respectively. This result was lower than that observed in a previous study between 2012 and 2016 in Basra (Al-Asadi and Ibrahim, 2018), and relatively similar to the incidence of some neighbouring countries, such as Iran (11.9 cases/100,000 individuals) (Shabani et al., 2020), Jordan (11.38 cases/100,000 individuals) (Al-Sheyyab et al., 2003) and Saudi Arabia (9.8 cases/100,000 individuals) (Al-Mutlaq et al., 2015).

In childhood patients, the cancer rate accounted for 3.9 and $4.8 \%$ of all registered cases in Erbil and Duhok, respectively, with the proportion of individuals considered children being $36 \%$, and the rate was less than the $7.75 \%$ reported in the first cancer report in Iraq, with the proportion of individuals considered children being $49 \%$ out of the Iraqi population (Al-Fouadi and Parkin, 1984). However, the cancer rate is in agreement with the results of the Jordanian child cancer rate of $7.75 \%$ (Khader et al., 2018), but much higher than that of some developed countries, where the frequency is $>1 \%$, such as in Norway and the UK, where the frequency was 0.4 and $0.5 \%$, respectively (Larsen et al., 2015).

The overall average of ASIR per 100,000 individuals in adolescents in the present study was 38.62 and 27.46 in Erbil and Duhok, respectively, which is higher than the rates reported in some developed countries, for example: 19.83 in Portugal, 21.1 in the US, 26.1 in Austria and 28.2 in Piedmont (Italy), respectively (Carreira et al., 2012; Karim-Kos et al., 2016; Isaevska et al., 2017). The frequency of all new cases in Erbil and Duhok was comparable to the frequency of the Iraqi Cancer Registry from 2018, and was much higher than in Western countries.

Haematological cancers were the most common type of cancer amongst children and adolescents, and were more prominent amongst male than female children. These data were in agreement with previous local studies (AlFouadi and Parkin, 1984; Khoshnaw et al., 2015; Al-Asadi and Ibrahim, 2018; Board, 2018) and most other parts of the world (Kaatsch, 2010; Steliarova-Foucher et al., 2017). 
Currently, the second most common type of cancer in Erbil is $\mathrm{KC}$, followed by lymphoma; in Duhok, it is soft tissues followed by brain cancer. However, these data were not in line with data reported by the Iraqi Cancer Registry (2018), which found cancers of the central nervous system (CNS) to be the second most common type of cancer, followed by lymphoma (Steliarova-Foucher et al., 2017). Amongst adolescents in the present study, lymphomas and CNS tumours, and lymphomas and soft tissue cancers were the second and third most common cancers in Erbil and Duhok, respectively. In Iraq as a whole, CNS cancers and lymphomas were the second and third most common types of cancer (Board, 2018)

Finally, BC is rare is women $<20$ old (Molah Karim et al., 2015), and the current study affirmed this, but the low incidence of $\mathrm{BC}$ cases reported amongst this age group was more aggressive than in older patients (Fabiano et al., 2020). Young age is an independent poor prognostic factor in BC (Fredholm et al., 2009). Hence, it is important to take $\mathrm{BC}$ screening programs at an earlier age into consideration.

The stages of cancer disease are classified according to the TNM staging system, and is stratified as 0 , I, II, III and IV (Roland et al., 2016). Results of previous studies concluded that two-thirds of global cancer deaths occurred in less developed countries as a result of late-stage diagnoses and lack of adequate treatments (Sankaranarayanan et al., 2005; Ferlay et al., 2015). It has been documented that several influencing factors can determine the late-stage diagnosis of cancer, such as inadequate screening tests, education and cultural awareness (Majid et al., 2009). The type of cancer is another important factor that determines the differences in cancer stages amongst patients. For example, LC, stomach, CRC, pancreatic and liver cancer were recorded to be amongst the highest frequency of late-stage diagnosed cancers compared with other types of cancers of the SC, PC, uterus and BC (Welsh Cancer Intelligence and Surveillance Unit, 2016; Bryan et al., 2018). However, the results of several Iraqi studies found that the majority of BC cases are detected at very advanced stages (Majid et al., 2009; Alwan, 2016; Alwan et al., 2017; Alwan et al., 2019). Therefore, to minimize the consequence of late stage diagnoses, persistent monitoring of cancer incidence by stage should be prioritized (WHO, 2017).

In terms of frequency distribution in the KRG between 2013 and 2019, the highest rates were recorded in the centre of Erbil, and the lowest in Mergasor, regarding the cancer risk distribution. In Duhok, the highest and lowest rates were reported respectively in Duhok centre and Berdehresh district. This is likely due to early detection through mammography screening programs in urban centres. By increasing the social role of women in urban areas, the social effects of exposure to cancer risk factors may promote cancer development, thus, in major cities, such as Erbil and Duhok, more prevalent compared to rural and small towns with lower population densities and differing lifestyles (Azizi et al., 2000).

Several limitations may influence the interpretations of cancer incidence trends discussed here. First, the lack of knowledge on cancer mortality burden and death certificates in the present study is more likely due to administrative bureaucracy, which affects the accuracy of cancer rates in this area. Second, local variations in cancer rates are defined primarily based on only two selected cancer registries (Erbil and Duhok), and missing differences for specific cancer sites in the Sulaymaniyah governorate. Third, the limitations of screening and imaging approaches in cancer detection centres may partly explain the low incidence rates for certain types of cancer, masking the real prevalence of the disease.

In conclusion, the top three types of cancer dominant in $\mathrm{KRG}$ are LC, female BC and haematological cancers. These analyses are mostly consistent with the latest studies indicating that $\mathrm{LC}$, female $\mathrm{BC}$ and $\mathrm{CRC}$ are the top three most prevalent cancer types in terms of incidence worldwide. The increase in trends of all prominent cancer types in the KRG region illustrate the urgent need to prioritize early diagnosis. In the present analyses, a high proportion of unknown primary cancers was observed, which could be due to limited diagnostic facilities in KRG. The urgent priorities to be addressed to minimize cancer incidence and mortality rates in KRG include developing and improving services concerned with cancer screening and early detection, aetiology of cancer, cancer registration and improved surveillance programs. Despite the challenges of accurate and comprehensive data collection, improved estimations and use of local data are strongly recommended in KRG for cancer registry development, to evaluate and support the national control efforts. Early cancer detection through various techniques and improved therapies is highly recommended to decrease the incidence of cancer over the next decade.

\section{Author Contribution Statement}

KMA, AMSA, HHN, DM, HEO, FMR, TSM and KM: Data curation, Writing- Original draft preparation. OSA, ASM, BH, SWK, ZAM, BTB, AMS, FMS, SASKA, GOO and MHA: Methodology, Software, Visualization, Investigation. MS, ZH, LRS, DKM, GQ, BMH, FAA, FAQ and DMT: Writing- Reviewing and Editing. AS: Conceptualization, Supervision.

\section{Acknowledgements}

Our special thanks are due to all staff members of the Erbil and Duhok cancer registry, cancer control units for their help, and our highest appreciation to Mrs Suad Bakir at Kurdistan Regional Statistics Office for providing the Kurdistan's population data.

\section{Ethics approval and consent to participate}

The present study was authorized and approved by the Human Ethics Committee of Salahaddin University-Erbil. Patients provided written informed consent.

\section{Patient consent for publication}

All patients provided written informed consent for the publication of data in the current study. 


\section{Competing interests}

The authors declare that they have no conflict of interests.

\section{References}

Abdel-Razeq H, Attiga F, Mansour A (2015). Cancer care in Jordan. Hematol Oncol Stem Cell Ther, 8, 64-70.

Al-Asadi JN, Ibrahim SJ (2018). Childhood Cancer in Basrah, Iraq During 2012-2016: Incidence and Mortality. Asian Pac $J$ Cancer Prev, 19, 2337-41.

Al-Fouadi A, Parkin DM (1984). Cancer in Iraq: seven years' data from the Baghdad Tumour Registry. Int $J$ Cancer, 34, 207-13.

Al-Hashimi MM, Wang XJ (2014). Trend analysis of lung cancer incidence rates in ninawa province, Iraq, from 2000 to 2010--decrease and recent stability. Asian Pac J Cancer Prev, 15, 385-90.

Al-Mutlaq HM, Bawazir AA, Jradi H, et al (2015). Patterns of childhood cancer incidence in Saudi Arabia (1999- 2008). Asian Pac J Cancer Prev, 16, 431-5.

Al-Sheyyab M, Bateiha A, Kayed SE, et al (2003). The incidence of childhood cancer in Jordan: a population-based study. Ann Saudi Med, 23, 260-3.

Alwan N, Kerr D (2018). Cancer control in war-torn Iraq. Lancet Oncol, 19, 291-2.

Alwan N, Nidhal F, Muallah M, et al (2017). The stage of breast cancer at the time of diagnosis: Correlation with the Clinicopathological Findings among Iraqi Patients. $J$ Neoplasm, 2, 1-10.

Alwan NAS (2016). Breast cancer among Iraqi women: Preliminary Findings From a Regional Comparative Breast Cancer Research Project. J Glob Oncol, 2, 255-8.

Alwan NAS, Tawfeeq FN, Mallah NAG (2019). Demographic and clinical profiles of female patients diagnosed with breast cancer in Iraq. J Contemporary Med Sci, $14-9 \% \mathrm{~V} 5$.

Anderson KN, Schwab RB, Martinez ME (2014). Reproductive risk factors and breast cancer subtypes: a review of the literature. Breast Cancer Res Treat, 144, 1-10.

Anton-Culver H (1995). Cancer prevention strategies: use of cancer prevention research registries. Environ Health Perspect, 103, 237-9.

Azizi F, Hatami H, Janghorbani M (2000). Epidemiology and control of common diseases in Iran. Tehran: Eshtiagh Publications, 602-16.

Baade PD, Youlden DR, Krnjacki LJ (2009). International epidemiology of prostate cancer: geographical distribution and secular trends. Mol Nutr Food Res, 53, 171-84.

Board IC (2018). Annual Report: Iraqi Cancer Registry.

Bray F, Ferlay J, Soerjomataram I, et al (2018). Global cancer statistics 2018: GLOBOCAN estimates of incidence and mortality worldwide for 36 cancers in 185 countries. $C A$ Cancer J Clin, 68, 394-424.

Bryan S, Masoud H, Weir HK, et al (2018). Cancer in Canada: Stage at diagnosis. Health Rep, 29, 21-5.

Carreira H, Antunes L, Castro C, et al (2012). Cancer incidence and survival (1997-2006) among adolescents and young adults in the north of Portugal. Pediatr Hematol Oncol, 29, 663-76.

Center MM, Jemal A, Smith RA, et al (2009). Worldwide variations in colorectal cancer. CA Cancer J Clin, 59, 366-78.

Esmaeimzadeh N, Salahi-Moghaddam A, Khoshdel A (2015). Geographic distribution of important cancers in Iran. Hormozgan Med J, 19.

Fabiano V, Mandó P, Rizzo M, et al (2020). Breast cancer in young women presents with more aggressive pathologic characteristics: Retrospective Analysis From an Argentine
National Database. JCO Glob Oncol, 6, 639-46.

Ferlay J, Colombet M, Soerjomataram I, et al (2019). Estimating the global cancer incidence and mortality in 2018: GLOBOCAN sources and methods. Int $J$ Cancer, 144, 1941-53.

Ferlay J, Soerjomataram I, Dikshit R, et al (2015). Cancer incidence and mortality worldwide: sources, methods and major patterns in GLOBOCAN 2012. Int $J$ Cancer, 136, E359-86.

Fitzmaurice C, Abate D, Abbasi N, et al (2019). Global, regional, and national cancer incidence, mortality, years of life lost, years lived with disability, and disability-adjusted life-years for 29 cancer groups, 1990 to 2017: A Systematic Analysis for the Global Burden of Disease Study. JAMA Oncol, 5, 1749-68.

Fredholm H, Eaker S, Frisell J, et al (2009). Breast cancer in young women: poor survival despite intensive treatment. PLoS One, 4, e7695.

Halahleh K, Gale RP (2018). Cancer care in the Palestinian territories. Lancet Oncol, 19, e359-e64.

Hassanipour-Azgomi S, Mohammadian-Hafshejani A, Ghoncheh $\mathrm{M}$, et al (2016). Incidence and mortality of prostate cancer and their relationship with the Human Development Index worldwide. Prostate Int, 4, 118-24.

Hon Z, Osterreicher J, Navrátil L (2015). Depleted Uranium and Its Effects on Humans. Sustainability, 7, 4063-77.

Howlader N, Noone A, Krapcho Me, et al (2020). SEER cancer statistics review, 1975-2017. Bethesda, MD: National Cancer Institute, 1423-37.

Huerta E, Grey N (2007). Cancer Control Opportunities in Lowand Middle-Income Countries. CA Cancer J Clin, 57, 72-4.

Hussain AM, Lafta RK (2021). Cancer Trends in Iraq 2000-2016. Oman Med J, 36, e219-e.

Hussain RA, Habib OS (2015). Incidence of cancer in Basrah: results of a household survey. Asian Pac J Cancer Prev, 16, 163-7.

IARC (2014). World cancer report 2014, World Health Organization.

Isaevska E, Manasievska M, Alessi D, et al (2017). Cancer incidence rates and trends among children and adolescents in Piedmont, 1967-2011. PLoS One, 12, e0181805.

Jemal A, Center MM, DeSantis C, et al (2010). Global patterns of cancer incidence and mortality rates and trends. Cancer Epidemiol Biomarkers Prev, 19, 1893-907.

Kaatsch P (2010). Epidemiology of childhood cancer. Cancer Treat Rev, 36, 277-85.

Karim-Kos HE, Hackl M, Mann G, et al (2016). Trends in incidence, survival and mortality of childhood and adolescent cancer in Austria, 1994-2011. Cancer Epidemiol, 42, 72-81.

Keum N, Giovannucci E (2019). Global burden of colorectal cancer: emerging trends, risk factors and prevention strategies. Nat Rev Gastroenterol Hepatol, 16, 713-32.

Khader YS, Sharkas GF, Arkoub KH, et al (2018). The epidemiology and trend of cancer in Jordan, 20002013. J Cancer Epidemiol, 2018, 2937067.

Khoshnaw N, Mohammed HA, Abdullah DA (2015). Patterns of cancer in Kurdistan - results of eight years cancer registration in Sulaymaniyah Province-Kurdistan-Iraq. Asian Pac J Cancer Prev, 16, 8525-31.

Larsen I, Møller B, Johannesen T, et al (2015). Cancer in Norway 2014. Cancer incidence, mortality, survival and prevalence in Norway, Oslo: Kreftregisteret Norge.

Majid RA, Mohammed HA, Saeed HM, et al (2009). Breast cancer in Kurdish women of northern Iraq: incidence, clinical stage, and case control analysis of parity and family risk. BMC Womens Health, 9, 33. 
McAllister EJ, Dhurandhar NV, Keith SW, et al (2009). Ten putative contributors to the obesity epidemic. Crit Rev Food Sci Nutr, 49, 868-913.

McDiarmid MA, Keogh JP, Hooper FJ, et al (2000). Health effects of depleted uranium on exposed Gulf War veterans. Environ Res, 82, 168-80.

Merletti F, Galassi C, Spadea T (2011). The socioeconomic determinants of cancer. Environ Health, 10, S7.

Molah Karim SA, Ali Ghalib HH, Mohammed SA, et al (2015). The incidence, age at diagnosis of breast cancer in the Iraqi Kurdish population and comparison to some other countries of Middle-East and West. Int J Surg, 13, 71-5.

Museedi OS, Younis WH (2014). Oral cancer trends in Iraq from 2000 to 2008. The Saudi Journal for Dental Research, 5, 41-7.

Popkin BM (2006). Global nutrition dynamics: the world is shifting rapidly toward a diet linked with noncommunicable diseases. Am J Clin Nutr, 84, 289-98.

Qader G, Aali M, Amen KM, et al (2020). The status of cancer publications in the Kurdistan region of Iraq. J Cancer Policy, 24, 100221

Rojas K, Stuckey A (2016). Breast cancer epidemiology and risk factors. Clin Obstet Gynecol, 59, 651-72.

Roland N, Porter G, Fish B, et al (2016). Tumour assessment and staging: United Kingdom National Multidisciplinary Guidelines. J Laryngol Otol, 130, 53-8.

Sankaranarayanan R, Nene BM, Dinshaw KA, et al (2005). A cluster randomized controlled trial of visual, cytology and human papillomavirus screening for cancer of the cervix in rural India. Int J Cancer, 116, 617-23.

Shabani M, Saeedi Moghaddam S, Ataeinia B, et al (2020). Trends of National and Subnational Incidence of Childhood Cancer Groups in Iran: 1990-2016. Front Oncol, 9, 1428-.

Siegel RL, Miller KD, Jemal A (2020). Cancer statistics, 2020. CA Cancer J Clin, 70, 7-30.

Smetana K, Jr., Lacina L, Szabo P, et al (2016). Ageing as an Important Risk Factor for Cancer. Anticancer Res, 36, 5009-17.

Steindel SJ (2010). International classification of diseases, 10th edition, clinical modification and procedure coding system: descriptive overview of the next generation HIPAA code sets. J Am Med Inform Assoc, 17, 274-82.

Steliarova-Foucher E, Colombet M, Ries LAG, et al (2017). International incidence of childhood cancer, 2001-10: a population-based registry study. Lancet Oncol, 18, 719-31.

Surdu S (2014). Non-melanoma skin cancer: occupational risk from UV light and arsenic exposure. Rev Environ Health, 29, 255-64.

Tarawneh M, Khatib S, Arqoub K (2010). Cancer incidence in Jordan, 1996-2005. Eastern Mediterranean health journal = La revue de santé de la Méditerranée orientale $=$ al-Majallah al-ṣiḥhīyah li-sharq al-mutawassiṭ, 16, 837-45.

World Health Organization (2003). International classification of diseases for oncology., World Health Organization: Geneva.

Yabroff KR, Lund J, Kepka D, et al (2011). Economic burden of cancer in the United States: estimates, projections, and future research. Cancer Epidemiol Biomarkers Prev, 20, 2006-14.

Yazdani-Charati J, Khosravi F, Moradi M, et al (2014). Mapping gastrointestinal cancer mortality in Kurdistan province. 1604. Transl Gastrointest Cancer , 3, 160-4.

\section{(c) (1) ()}

This work is licensed under a Creative Commons AttributionNon Commercial 4.0 International License. 